\title{
DERIVING A DOSE AND REGIMEN FOR ANTI-GLUCOSAMINIDASE ANTIBODY PASSIVE-IMMUNISATION FOR PATIENTS WITH STAPHYLOCOCCUS AUREUS OSTEOMYELITIS
}

\author{
C.C. Lee ${ }^{1}$, R.D. Southgate ${ }^{1}$, C. Jiao ${ }^{1}$, E. Gersz ${ }^{1}$, J.R. Owen², S.L. Kates ${ }^{2}$, C.A. Beck ${ }^{1}$, C. Xie ${ }^{1}$, J.L. Daiss ${ }^{1}$, \\ V. Post ${ }^{3}$, T.F. Moriarty ${ }^{3}$, S. Zeiter ${ }^{3}$, E.M. Schwarz ${ }^{1, *}$ and G. Muthukrishnan ${ }^{1}$ \\ ${ }^{1}$ Centre for Musculoskeletal Research, University of Rochester Medical Centre, Rochester, NY, USA \\ ${ }^{2}$ Department of Orthopaedic Surgery, Virginia Commonwealth University, Richmond, VA, USA \\ ${ }^{3} \mathrm{AO}$ Research Institute Davos, Davos, Switzerland
}

\begin{abstract}
Staphylococcus aureus (S. aureus) osteomyelitis remains a major clinical problem. Anti-glucosaminidase (Gmd) antibodies (1C11) are efficacious in prophylactic and therapeutic murine models. Feasibility, safety and pharmacokinetics of 1C11 passive immunisation in sheep and endogenous anti-Gmd levels in osteomyelitis patients were assessed.

3 sheep received a $500 \mathrm{mg}$ intravenous (i.v.) bolus of $1 \mathrm{C} 11$ and its levels in sera were determined by enzyme-linked immunosorbent assay (ELISA) over $52 \mathrm{~d}$. A humanised anti-Gmd monoclonal antibody, made by grafting the antigen-binding fragment $(\mathrm{Fab})$ portion of $1 \mathrm{C} 11$ onto the fragment crystallisable region $(\mathrm{Fc})$ of human IgG1, was used to make a standard curve of mean fluorescent intensity versus concentration of antiGmd. Anti-Gmd serum levels were determined in 297 patients with culture-confirmed S. aureus osteomyelitis and 40 healthy controls.

No complications or adverse events were associated with the sheep 1C11 i.v. infusion and the estimated circulating half-life of $1 \mathrm{C} 11$ was $23.7 \mathrm{~d}$. Endogenous anti-Gmd antibody levels in sera of osteomyelitis patients ranged from $<1 \mathrm{ng} / \mathrm{mL}$ to $300 \mu \mathrm{g} / \mathrm{mL}$, with a mean concentration of $21.7 \mu \mathrm{g} / \mathrm{mL}$. The estimated circulating half-life of endogenous anti-Gmd antibodies in sera of 12 patients with cured osteomyelitis was $120.4 \mathrm{~d}$.

A clinically relevant administration of anti-Gmd (500 mg i.v. $=7 \mathrm{mg} / \mathrm{kg} / 70 \mathrm{~kg}$ human) was safe in sheep. This dose was 8 times more than the endogenous anti-Gmd levels observed in osteomyelitis patients and was predicted to have a half-life of $>3$ weeks.

Anti-Gmd passive immunisation has potential to prevent and treat $S$. aureus osteomyelitis. Further clinical development is warranted.
\end{abstract}

Keywords: Orthopaedic infections, immunoassay, Staphylococcus aureus, osteomyelitis, peri-prosthetic joint infection, 2-stage revision surgery, passive immunisation.

*Address for correspondence: Edward M. Schwarz, PhD, Burton Professor of Orthopaedics, Director of Centre for Musculoskeletal Research, University of Rochester Medical Centre, 601 Elmwood Avenue, Box 665, 14642, Rochester, NY, USA.

Telephone number: +1 5852753063 Email: Edward_schwarz@urmc.rochester.edu

Copyright policy: This article is distributed in accordance with Creative Commons Attribution Licence (http://creativecommons.org/licenses/by-sa/4.0/).

\begin{tabular}{|c|c|c|c|}
\hline & List of Abbreviations & $\mathrm{Fc}$ & fragment crystallisable region \\
\hline & & FDA & Food and Drug Administration \\
\hline AAALAC & Assessment and Accreditation of & Gmd & glucosaminidase \\
\hline Amd & Laboratory Animal Care & IACUC & Institutional Animal Care and Use \\
\hline $\begin{array}{l}\text { Amd } \\
\text { Atl }\end{array}$ & $\begin{array}{l}\text { amidase } \\
\text { autolysin }\end{array}$ & ICC & $\begin{array}{l}\text { Committee } \\
\text { intraclass correlation coefficient }\end{array}$ \\
\hline CI & confidence interval & IRB & Institutional Review Board \\
\hline $\mathrm{CV}$ & column volume & i.v. & intravenous \\
\hline ELISA & $\begin{array}{l}\text { enzyme-linked immunosorbent } \\
\text { assay }\end{array}$ & $\begin{array}{l}\text { LLOD } \\
\text { mAb }\end{array}$ & $\begin{array}{l}\text { lower limit of detection } \\
\text { monoclonal antibody }\end{array}$ \\
\hline
\end{tabular}




\begin{tabular}{|c|c|}
\hline MFI & median fluorescent intensity \\
\hline MRSA & $\begin{array}{l}\text { methicillin-resistant Staphylococcus } \\
\text { aureus }\end{array}$ \\
\hline PBS & phosphate-buffered saline \\
\hline PE & phycoerythrin \\
\hline PJI & peri-prosthetic joint infection \\
\hline SACs & Staphylococcus abscess communities \\
\hline SCIP & Surgical Care Improvement Project \\
\hline SDS-PAGE & $\begin{array}{l}\text { sodium dodecyl sulphate- } \\
\text { polyacrylamide gel electrophoresis }\end{array}$ \\
\hline SEM & standard error of the mean \\
\hline HA & total hip arthroplasty \\
\hline TKA & total knee arthroplasty \\
\hline UCB & upper confidence bound \\
\hline
\end{tabular}

\section{Introduction}

Bone infection, also known as osteomyelitis, remains a catastrophic complication of orthopaedic surgery. Most cases are caused by Staphylococcus aureus (S. aureus) (Darouiche, 2004). Although clinical algorithms have been established to prevent these biofilm infections that are resistant to antibiotic therapy (Saeed et al., 2019), the current incidence of PJI ranges from 0.2 to $1.5 \%$ (Schwarz et al., 2019). Moreover, it appears that significant improvements are not possible, as implementation of the most rigorous protocols [e.g. outcomes from the SCIP (Stulberg et al., 2010)] has demonstrated that infection rates for elective surgery cannot be reduced below 1-2 \% (Cram et al., 2012). Additionally, on top of the clinical complications, the enormous costs for treating osteomyelitis threaten healthcare systems, as they are projected to exceed $\$ 1.62$ billion in the USA by 2020 (Kurtz et al., 2012).

The prevalence of $S$. aureus osteomyelitis is due to the various pathogenic mechanisms that this commensal pathogen has evolved to facilitate immune evasion, including:

- biofilm formation on the implant (Nishitani et al., 2015b) and necrotic bone (Birt et al., 2017; Lew and Waldvogel, 2004);

- generation of SACs in soft tissues and bone marrow (Cheng et al., 2009; Varrone et al., 2014; Yokogawa et al., 2018);

- ability to colonise the osteocytic-canalicular network of live cortical bone (de Mesy Bentley et al., 2018; de Mesy Bentley et al., 2017).

Thus, reinfection rates following surgery for $S$. aureus osteomyelitis are very high (15-40\%) and often require an implant-exchange surgery to remedy the problem (Azzam et al., 2009; Ferry et al., 2009; Ghanem et al., 2009; Parvizi et al., 2009; Salgado et al., 2007).

Although active immunisations are the most cost-effective interventions for infectious diseases, enormous efforts to develop a $S$. aureus vaccine have been unsuccessful for various reasons (Jansen et al., 2013; Proctor, 2012; Proctor, 2015). Moreover, active vaccinations targeting endogenous pathobionts such as $S$. aureus may boost pre-existing immune responses, which may be ineffective or may even have debilitating effects. These failures have led to conflict in the field with regard to the role of humoral immunity during $S$. aureus infections and reservations about active vaccination therapy's potential to treat serious surgical site infections (Bagnoli et al., 2012; Fowler and Proctor, 2014; Pier, 2013; Proctor, 2012; Projan et al., 2006). This raging controversy has been amplified by the occurrence of patient deaths in a large phase II clinical trial of the V710 vaccine (Fowler et al., 2013; McNeely et al., 2014), posing the question of how the extensive pre-clinical research programme leading up to a clinical trial with 8,000 patients could have reached the wrong conclusions regarding the vaccine safety and efficacy for the intended clinical indication (Harro et al., 2012; Kim et al., 2010). However, this pessimism is tempered by the recent transformative successes of cancer mAb-based passive immunotherapies after decades of disappointments, for which the 2018 Nobel Prize in Physiology or Medicine was awarded to Dr James Allison and Dr Tasuku Honjo for their seminal discoveries of immune checkpoint inhibitors (Smyth and Teng, 2018). Thus, the quest for an S. aureus vaccine continues.

The overall hypothesis of the passive immunotherapy programme has been that the most effective $m A$ bs would have dual-acting mechanisms of action, both directly inhibiting functions critical to S. aureus and mediating immunomodulatory activity to boost host response and bacterial clearance. By using a non-biased research approach to test this hypothesis, the Gmd subunit of $S$. aureus Atl was identified as the lead target (Gedbjerg et al., 2013; Varrone et al., 2014; Varrone et al., 2011b; Yokogawa et al., 2018). Of note is that other groups have also identified Atl as an immunodominant antigen (Brady et al., 2011; Gotz et al., 2014; Holtfreter et al., 2010). Functionally, Atl is essential for cell-wall degradation and biosynthesis during binary fission (Oshida et al., 1995; Sugai et al., 1995; Yamada et al., 1996). In addition, Atl acts as an adhesin (Heilmann et al., 2005), a biofilm enzyme (Brady et al., 2006) and a facilitator of host cellular internalisation/immune evasion (Hirschhausen et al., 2010). Remarkably, S. aureus Amd, which is the other subunit of Atl, known to activate platelet activation and aggregation (Binsker et al., 2018), was shown to be a molecular target of vancomycin (Eirich et al., 2011), which is the most common antibiotic used to treat MRSA infections. Importantly, anti-Gmd passive immunisation has been shown to synergise with vancomycin therapy in rabbit and murine infection models (Brady et al., 2011; Kalali et al., 2019; Yokogawa et al., 2018). Additionally, clinical research studies to assess humoral immunity in patients with osteomyelitis from PJI, trauma and diabetic foot ulcers have identified anti-Gmd antibodies in patients that recover from these serious infections (Gedbjerg et al., 2013; Nishitani et al., 2015a; Oh et al., 2018). 
To evaluate the potential of anti-Gmd $\mathrm{mAb}$ passive immunisation in murine models of osteomyelitis, 36 anti-Gmd-producing murine hybridomas were screened for their ability to bind recombinant Gmd, inhibit its enzymatic activity in a cell-wall digestion assay and precipitate $S$. aureus out of culture (Gedbjerg et al., 2013; Varrone et al., 2014; Varrone et al., 2011a). Of these, one IgG1 mAb (1C11) displayed superior properties based on its:

- clinically relevant affinity $\left(\mathrm{k}_{\mathrm{f}}=3.1 \times 10^{4} \mathrm{M}^{-1} \mathrm{~s}^{-1}\right.$; $\mathrm{k}_{\mathrm{r}}=5.0 \times 10^{-5} \mathrm{~s}^{-1} ; \mathrm{K}_{\mathrm{D}}=1.6 \times 10^{-9} \mathrm{M}$ ) (Varrone et al., 2014);

- stoichiometric neutralising activity (Gedbjerg et al., 2013);

- phenocopy of Gmd deficient S. aureus mutants (Varrone et al., 2014);

- ability to mediate $S$. aureus megacluster formation and opsonophagocytosis in vitro (Varrone et al., 2014);

- ability to protect mice from MRSA osteomyelitis (8 out of 17 animals demonstrated undetectable MRSA levels in the 1C11 group as compared to 1 out of 15 in the placebo group) (Varrone et al., 2014);

- ability to synergise with vancomycin to cure mice with established osteomyelitis [combination therapy yielded a 6.5-fold reduction in MRSA levels ( 7 out of 10 animals) as compared to untreated animals] (Yokogawa et al., 2018).

Although 1C11 does not inhibit bacteria within biofilms, these promising results warrant further research to transform the established rodent dosing regimen $(40 \mathrm{mg} / \mathrm{kg}$ through intraperitoneal injection) to that of FDA-approved biologics (e.g. infliximab Remicade $^{\circledR}$, trastuzumab Herceptin ${ }^{\circledR}$, rituximab Rituxan $^{\circledR}$, which are chimaeric mAb) administered as an i.v. infusion in the order of $500 \mathrm{mg} / \mathrm{L}$ saline (7 $\mathrm{mg} / \mathrm{kg}$ for a $70 \mathrm{~kg}$ patient). Clinical research is also needed to assess endogenous anti-Gmd levels in osteomyelitis patients. Thus, 1C11 passive immunisation of sheep was evaluated and the concentration of circulating anti-Gmd antibodies in patients with $S$. aureus osteomyelitis was quantified.

\section{Materials and Methods}

\section{Large scale production of $1 \mathrm{C} 11 \mathrm{mAb}$}

A pilot study to assess feasibility, safety and pharmacokinetics of passively immunising adult sheep was performed at the AO Research Institute (Davos, Switzerland) based on IACUC-approved protocols. To generate the test material, $2 \mathrm{~g}$ of $1 \mathrm{C} 11$ $\mathrm{mAb}$ were produced from a well-characterised 1C11 hybridoma cell line (Gedbjerg et al., 2013; Varrone et al., 2014) in the Upstate Stem cGMP Facility (USCGF, University of Rochester, Rochester, NY, USA). Following adaptation to HyClone SFM4Mab medium with $1 \%$ foetal bovine serum (Thermo Fisher Scientific), an initial $1 \mathrm{~L}$ inoculum of 1C11 hybridoma cells $\left(1.5 \times 10^{5}\right.$ viable cells $/ \mathrm{mL}$,
$1 \mathrm{C} 11=18.6 \mu \mathrm{g} / \mathrm{mL}$ ) was placed in a $5 \mathrm{~L}^{\text {Cellbag }}{ }^{\mathrm{TM}}$ for WAVE Bioreactor ${ }^{\mathrm{TM}}$ (GE Healthcare Life Sciences) at $37^{\circ} \mathrm{C}$. As the viable cell count reached $\sim 8.2 \times 10^{5}$ cells/ $\mathrm{mL}(1 \mathrm{C} 11=56.8 \mu \mathrm{g} / \mathrm{mL})$, an additional $1.5 \mathrm{~L}$ of $1 \%$ serum-containing medium was added. Following dilution of the culture with additional medium, the viable cell count expanded to $\sim 1 \times 10^{6}$ cells $/ \mathrm{mL}$ $(1 \mathrm{C} 11=109.2 \mu \mathrm{g} / \mathrm{mL})$. At that point, $2 \mathrm{~L}$ of culture were harvested and $2 \mathrm{~L}$ of $1 \%$ serum medium was added to replace the volume in the Cellbag ${ }^{\mathrm{TM}}$. As the cell population increased $\left(1.8 \times 10^{6}\right.$ cells $/ \mathrm{mL}, 33 \mu \mathrm{g} /$ $\mathrm{mL})$, an additional $2 \mathrm{~L}$ of culture was harvested and $1 \mathrm{~L}$ of serum-free medium added, bringing the total serum concentration to approximately $0.2 \%$. As the cell count remained stationary at $\sim 7 \times 10^{5}$ cells $/ \mathrm{mL}$, another $1.5 \mathrm{~L}$ of $0.2 \%$ serum medium was added. After an initial lag in cell growth, the population of 1C11 hybridoma cells resumed growth and $2 \mathrm{~L}$ of product were harvested, followed by the addition of $1 \mathrm{~L}$ of serum-free medium, bringing the effective medium serum concentration to $0 \%$. At this point, 1 C11 cells $\left(3.9 \times 10^{5}\right.$ cells $\left./ \mathrm{mL}\right)$ were fully adapted to serum-free medium. With minimal lag, cells reached a cell count of $1.09 \times 10^{6}$ cells $/ \mathrm{mL}(45.3 \mu \mathrm{g} / \mathrm{mL})$, so an additional $1 \mathrm{~L}$ serum-free medium was added, followed shortly thereafter with harvesting of the entire $2 \mathrm{~L}$ content of the Cellbag ${ }^{\mathrm{TM}}\left(1.6 \times 10^{6}\right.$ cells $/ \mathrm{mL}$, $74.4 \mu \mathrm{g} / \mathrm{mL}$ ). In total, $8 \mathrm{~L}$ of product were obtained from the entire Cellbag ${ }^{\mathrm{TM}}$ adaptation run, with an estimated antibody production of $\sim 90 \mu \mathrm{g} / \mathrm{mL}$. The $8 \mathrm{~L}$ of culture were harvested in 4 independent $2 \mathrm{~L}$ harvests. The culture was processed by microfiltration using a Millipore filtration system with Pellicon ${ }^{\circledR}$ filter (0.22 $\mu \mathrm{m}$ Durapore ${ }^{\circledR}$ microfiltration membrane) to separate the cells, yielding $\sim 2$ L of clarified culture supernatant. The clarified culture supernatant was subsequently concentrated $\sim 5$.7-fold to a final volume of $350 \mathrm{~mL}$ using a $30 \mathrm{kDa}$ molecular weight cutoff ultrafiltration membrane. The concentrate was aliquoted and stored at $-20^{\circ} \mathrm{C}$.

\section{Purification of the $1 \mathrm{C} 11 \mathrm{mAb}$}

A $60 \mathrm{~mL}$ aliquot of concentrated culture supernatant ( $30 \mathrm{mg}$ of 1C11 $\mathrm{mAb}$ ) was thawed and loaded directly onto a MAbSelect SuRE LX Protein A column (GE Healthcare Life Sciences) equilibrated in $25 \mathrm{mM} \mathrm{NaPO} / 0.15 \mathrm{M} \mathrm{NaCl}$ ( $\mathrm{pH}=7.2)$ using an ÄKTAprime chromatography system (GE Healthcare Life Sciences) and a flow rate of $2.5 \mathrm{~mL} /$ min. Post loading and washing of the column with equilibration buffer ( $\mathrm{pH}=7.2), 60 \mathrm{~mL}$ of the $1 \mathrm{C} 11$ antibody culture supernatant were again added to the column. Following loading, the unbound protein was washed through the column with five CVs $(1 \mathrm{CV}=5 \mathrm{~mL})$ of equilibration buffer. Following column wash, elution of the $1 \mathrm{C} 11$ product was accomplished by application of a linear gradient $(0-0.1 \mathrm{M})$ of sodium citrate $(\mathrm{pH}=3.0)$. Elution of the bound $1 \mathrm{C} 11 \mathrm{mAb}$ was effected with a $\mathrm{pH}$ gradient from 7.2 to 3.0 over $10 \mathrm{CVs}(2.5 \mathrm{~mL}$ fractions were collected). Fig. 1 describes the results of a typical run 
in which $~ 30.8 \mathrm{mg}$ of $1 \mathrm{C} 11$ antibody in concentrated culture supernatant was loaded onto the column and $\sim 23.0 \mathrm{mg}$ of $99 \%$ pure mAb were recovered, resulting in an overall yield of $74.7 \%$. This process was repeated until $2 \mathrm{~g}$ of $1 \mathrm{C} 11$ antibody were purified. The protein integrity was confirmed by SDS-PAGE stained with Coomassie Brilliant Blue according to manufacturer's recommendations (BioRad). The antigen binding activity of the purified 1C11 antibody was demonstrated by ELISA

\section{Passive immunisation of sheep and pharmacokinetic} assessment in sera

Three adult (2 years), healthy (based on clinical examination and blood analysis) Swiss Alpine female sheep weighing $56-57.5 \mathrm{~kg}$ were acclimatised for 2 weeks. During this time, as well as after the infusion, they were group-housed and fed twice per day with hay and mineral lick at their disposal. Each sheep was given a $500 \mathrm{mg}$ i.v. bolus of mouse IgG1 1C11 $\mathrm{mAb}$ in $1 \mathrm{~L}$ of Ringer's solution over a period of $3 \mathrm{~h}$. During infusion, sheep's physiological parameters were observed by a veterinarian. These included heart rate, respiration rate, temperature and anaphylactic reaction. Post infusion, sheep were monitored daily for the first $10 \mathrm{~d}$ and weekly thereafter using a customised score sheet (temperature increases, potential infusion site infections, weight gain/loss and faeces changes). Blood was withdrawn for haematological analyses including complete blood
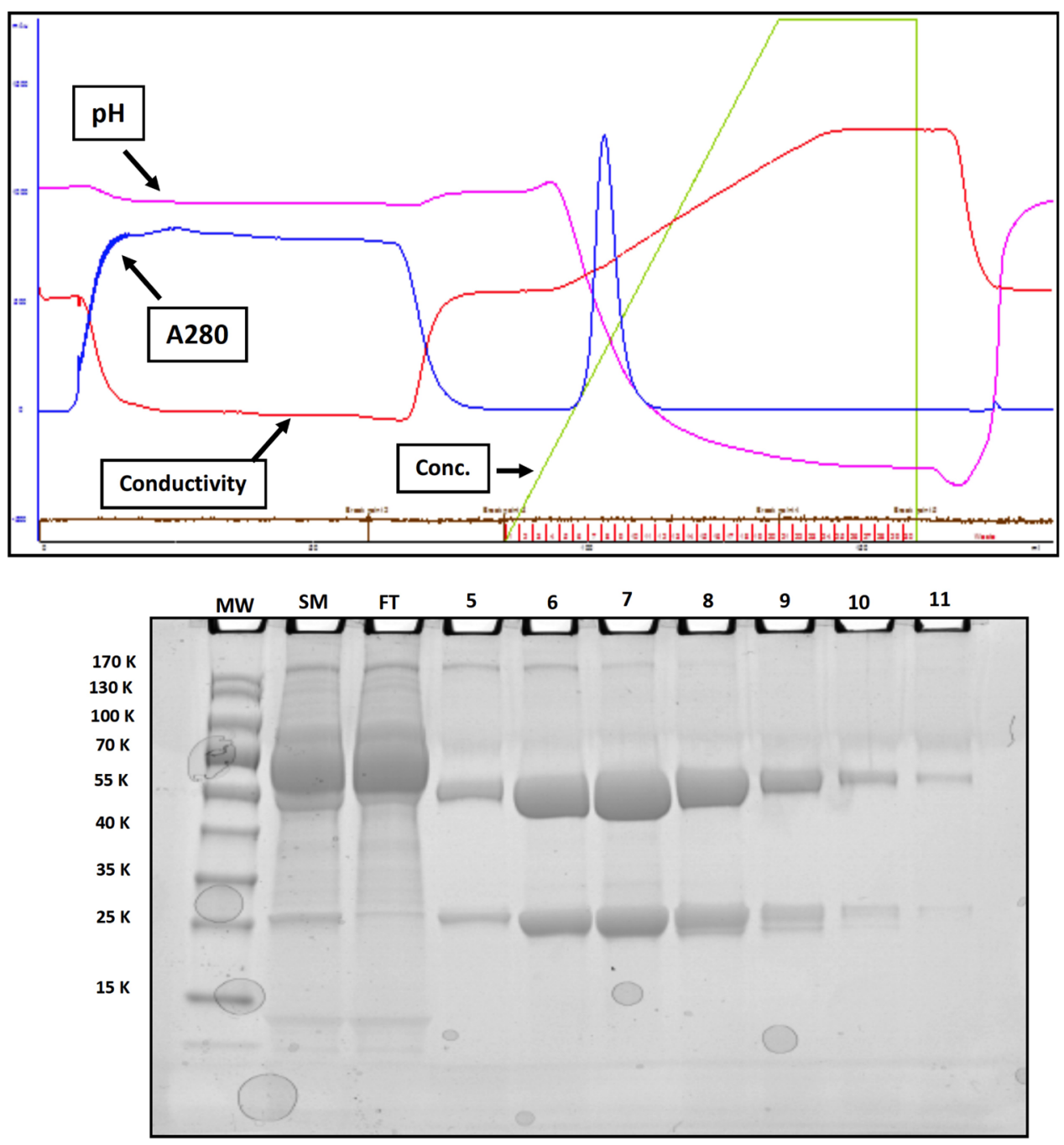

Fig. 1. Large scale purification of $1 \mathrm{C} 11 \mathrm{mAb}$. Large scale protein purification of $1 \mathrm{C} 11 \mathrm{mAb}(\sim 30 \mathrm{mg}$ in $60 \mathrm{~mL}$ of concentrated hybridoma culture supernatant) was performed using an ÄKTAprime chromatography system as described in Materials and Methods. Biochemistry data on a representative run are shown to illustrate the process and the purity and integrity of the resulting product. (Top) Real-time data acquisition of the eluate was performed to assess $\mathrm{pH}$, protein concentration (A280), chemoelectrical conductivity and sodium citrate elution buffer during the chromatography run. Results are presented in an overlaid graph format. Of note is the sharp elution of the antibody (narrow blue peak of A280 midway through the run), which corresponds to the $2.5 \mathrm{~mL}$ elution fractions 6 to 9. (Bottom) An image of a Coomassie Brilliant Blue-stained denatured SDS-PAGE gel of molecular weight standard (MW), starting material (SM), flow through (FT) and elution fractions 5-11 is shown to illustrate the relative purification of the heavy $(53 \mathrm{kDa})$ and light $(25 \mathrm{kDa})$ chains of the $1 \mathrm{C} 11 \mathrm{mAb}$. In this run, $30.8 \mathrm{mg}$ of protein was loaded on to the column and $23.0 \mathrm{mg}$ of $99 \%$ pure $\mathrm{mAb}$ was recovered, giving a $74.7 \%$ yield. 
count, total protein, serum electrolytes, blood urea nitrogen and creatinine before and after infusion as well as twice per week thereafter.

Additionally, blood was taken $1 \mathrm{~h}$ post infusion (to determine $\mathrm{C}_{0}$ ) daily for 2 weeks and then weekly for 2 months. Serum was prepared from each blood sample and stored frozen at $-20{ }^{\circ} \mathrm{C}$ until all samples were collected. Then, $2 \mathrm{~mL}$ aliquots of the entire collection were assayed for anti-Gmd antibody activity by sandwich ELISA using recombinant histidine-tagged Gmd protein for capture and horseradish-peroxidaseconjugated anti-murine IgG1 antibody for detection, as previously described (Varrone et al., 2014).

All in vivo work was carried out at the AO Research Institute Davos, Switzerland, in an AAALACInternational-approved facility and according to the Swiss animal protection law and regulations (approval number 05_2013).

\section{Assessment of anti-Gmd antibody levels in human} sera by Luminex assay

All human-subject research was performed following IRB-approved protocols. A worldwide clinical registry of 297 patients with culture-confirmed $S$. aureus osteomyelitis was established in 2013 and completed in 2018 (Kates et al., 2019). This registry contains three serum samples (0 month, diagnosis of infected implant; 6 months, re-implantation; 12 months, follow up) from each patient. For the present study, anti-Gmd antibody titers were determined from the 297 patients of the AO5 registry and 40 uninfected healthy controls. To quantify the relative concentration of anti-Gmd antibodies in the sera, a mouse-human chimaeric $1 \mathrm{C} 11 \mathrm{mAb}$ was generated by replacing the murine $\mathrm{Fc}_{\mathrm{c}}$ with the human Fc IgG1, while retaining the murine $\mathrm{V}$ region

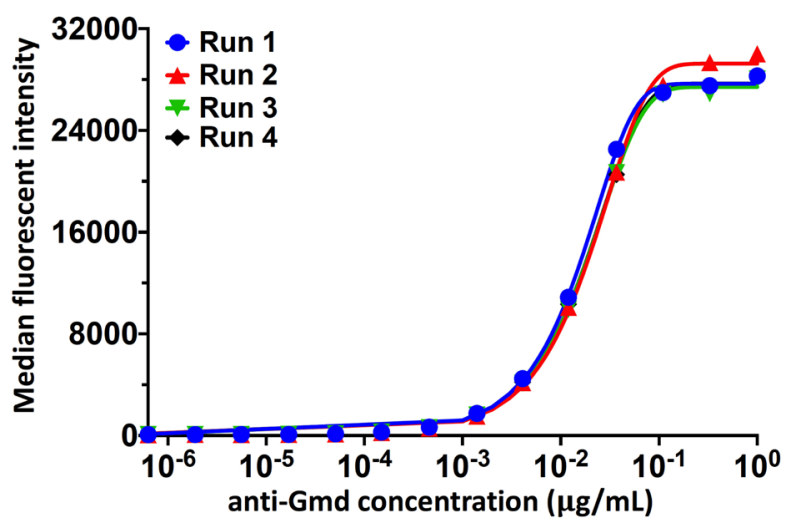

Fig. 2. Standard curves of the humanised $1 C 11$ chimaeric anti-Gmd $\mathbf{m A b}$. Standard curves of the MFI vs. concentration of the chimaeric 1C11 anti-Gmd antibody were generated using Luminex immunoassay starting at $1 \mu \mathrm{g} / \mathrm{mL}$ and serially diluting 3-fold down 14 times. This experiment was performed 4 independent times $(n=4)$ and the data from the 4 runs are superimposed in the graph. Highly significant reproducibility was achieved between the experiments, as illustrated by an ICC of 0.9984 [95 \% CI: 0.9964-0.9994, $p=1 \mathrm{e}^{-23}$ ]. of the $\mathrm{mAb}$, using a proprietary method (US Patent 9,683,054; BioAtla Inc., San Diego, CA, USA). Thus, this chimaeric $\mathrm{mAb}$ had the same antigen-binding characteristics as 1C11 but could be recognised by the anti-human IgG secondary antibody used in the Luminex assay.

The Luminex assay was performed as previously described (Nishitani et al., 2015a). Briefly, $6.5 \mu \mathrm{m}$ avidin-coated magnetic beads (MagPlex-Avidin Microspheres, Luminex Corporation, Austin, TX, USA) were coupled to recombinant biotinylated glucosaminidase protein (GenScript USA Inc., Piscataway, NJ, USA). A standard curve was generated with the chimaeric $1 \mathrm{C} 11 \mathrm{mAb}$, in which the starting concentration of $1 \mu \mathrm{g} / \mathrm{mL}$ was serially diluted 3-fold 14 times. The mAb was incubated with 1,000 Gmd-coupled magnetic microspheres per well of a Luminex immunoassay 96-well plate. After a $2 \mathrm{~h}$ incubation, the plate was washed using an automatic plate washer (BioTek 405TS microplate washer, BioTek Instruments, Inc., Winooski, VT, USA), $100 \mu \mathrm{L}$ of the secondary PE-conjugated anti-human IgG (Southern Biotech, Birmingham, AL, USA) were added to each well and the plate was incubated for $1 \mathrm{~h}$. Duplicate samples were analysed on a flow cytometer (Luminex 200, Luminex Corporation) to generate the standard curve of anti-Gmd titer MFI versus concentration of chimaeric anti-Gmd $\mathrm{mAb}$ $(\mu \mathrm{g} / \mathrm{mL})$ (Fig. 2). The aggregate LLOD for anti-Gmd antibody titers was utilised to define the threshold of detection. LLOD was calculated using the formula LLOD $=$ MFI of assay buffer $+2 \times$ SEM of assay buffer MFI (Nishitani et al., 2015a; Oh et al., 2018). An MFI of 95 when projected on the anti-Gmd 1C11 standard curve corresponded to $0.0139 \mathrm{ng} / \mathrm{mL}$. Thus, although Luminex assays typically have detection thresholds in the $\mathrm{pg} / \mathrm{mL}$ range, similar to that found with the $\mathrm{mAb}$, a more conservative approach was used to set the limit of detection at $1 \mathrm{ng} / \mathrm{mL}$, which took the large dilution factor $(1: 10,000)$ into consideration. Therefore, the values measured were the true anti-Gmd 1C11 levels in serum of patients with $S$. aureus osteomyelitis. The experiment was performed 4 independent times and highly significant reproducibility was achieved between the experiments, as illustrated by an ICC of 0.9984 [95 \% CI: 0.9964-0.9994, $p=1 \mathrm{e}^{-23}$ ].

To determine the anti-Gmd antibody titers in human sera, the same Luminex assay was performed by incubating $100 \mu \mathrm{L}$ of $1: 10,000$ diluted serum in PBS with the Gmd-MagPlex-Avidin Microspheres and then the secondary PE-conjugated anti-human IgG. MFI values were interpolated from the chimaeric 1C11 standard curve considering the $1: 10,000$ dilution factor to determine the concentration of anti-Gmd antibody in each serum sample.

\section{Data analyses}

Decay curves to determine antibody half-life of 1 C11 in sheep $(n=3)$ were generated in GraphPad Prism version 8.0 , in which the mean concentration at each time point was used to generate the best fit curve and 
the time at which $50 \%$ of the $\mathrm{C}_{0}$ was observed was determined to be the circulating antibody half-life. To determine the proportion of AO5 sera with an antiGmd concentration above uninfected control levels, UCB analyses were performed in which the $95 \%$ UCB for the control group was used as a threshold.

\section{Results}

\section{Circulating half-life of murine 1C11 anti-Gmd mAb} in sheep

Based on the demonstration of the safety and efficacy of 1C11 anti-Gmd passive immunisation in prophylactic (Varrone et al., 2014) and therapeutic (Yokogawa et al., 2018) models of implant-associated osteomyelitis, the present study aimed to establish preliminary safety and pharmacokinetic data in sheep, whose total body mass $(\sim 56 \mathrm{~kg})$ and dosing capacity ( $500 \mathrm{mg}$ of $\mathrm{mAb}$ in $1 \mathrm{~L}$ of saline, i.v.) are similar to humans. Thus, $2 \mathrm{~g}$ of $1 \mathrm{C} 11 \mathrm{mAb}$ were manufactured and administered to 3 adult sheep in a single i.v. infusion. Circulating levels of murine IgG1 (1C11 mAb) were assessed over the next $52 \mathrm{~d}$ (Fig. 3). There were no complications or adverse events associated with the $1 \mathrm{C} 11 \mathrm{mAb}$ passive immunisation in any of the sheep and the serology results demonstrated a steady decay with a half-life of $\sim 23.7 \mathrm{~d}$. Thus, this dosing regimen was deemed to be safe and appropriate for assessment of $1 \mathrm{C} 11$ $\mathrm{mAb}$ efficacy in a sheep model of implant-associated osteomyelitis (Moriarty et al., 2017).

An additional consideration for treatment of atrisk patients with prophylactic anti-Gmd mAb 1C11 is the likelihood that treatment will elicit a potentially neutralising sheep anti-mouse (or anti-human) response. To address this concern, the abundance of sheep anti-mouse IgG (heavy and light chain) antibody present in the serum of each sheep was measured at the time of administration (day 0) and 4 weeks later (day 28). Expectedly, no evidence for emergence of an anti-mouse response was found at this relatively early time point (data not shown).

\section{Circulating levels and natural decay of endogenous anti-Gmd antibodies in patients with $S$. aureus osteomyelitis}

To support a human dose and regimen of anti-Gmd $\mathrm{mAb}$ passive immunisation as an adjuvant therapy for $S$. aureus osteomyelitis, naturally occurring levels were assessed in these patients and healthy controls. Fig. 4 shows the relative concentration of anti-Gmd antibodies in the serum of 297 patients at the time of their revision surgery (active infection), compared to the mean concentration of anti-Gmd in sera of 40 uninfected healthy controls. Anti-Gmd antibody concentrations in the patient sera ranged from undetectable $(<1 \mathrm{ng} / \mathrm{mL})$ to $300 \mu \mathrm{g} / \mathrm{mL}$. The concentration of anti-Gmd in the median patient was $21.7 \mu \mathrm{g} / \mathrm{mL}$, which was within the range of uninfected control sera $(25.6 \pm 28.6 \mu \mathrm{g} / \mathrm{mL})$. Interestingly, only $104(35.0 \%)$ patients had circulating anti-Gmd antibody levels significantly above the mean of healthy people $(p<0.05$ using a $95 \% \mathrm{UCB}=33.2 \mu \mathrm{g} /$ $\mathrm{mL}$ ), suggesting that most $S$. aureus osteomyelitis patients failed to develop an immune response against this antigen and that passive-immunisation with a protective anti-Gmd $\mathrm{mAb}$ was indicated for a large majority of these patients.

To gain insight into a clinically relevant dosing regimen of anti-Gmd $\mathrm{mAb}$ immunotherapy for chronic osteomyelitis, for which the standard of care is 6 to 8 weeks of i.v. antibiotic therapy (Masters et al., 2019), the decay of circulating anti-Gmd antibodies was assessed within this patient cohort, over their 1-year treatment period. There were two major prerequisites for inclusion: 1) the patient completed the 1-year follow up period, 2) the patient was

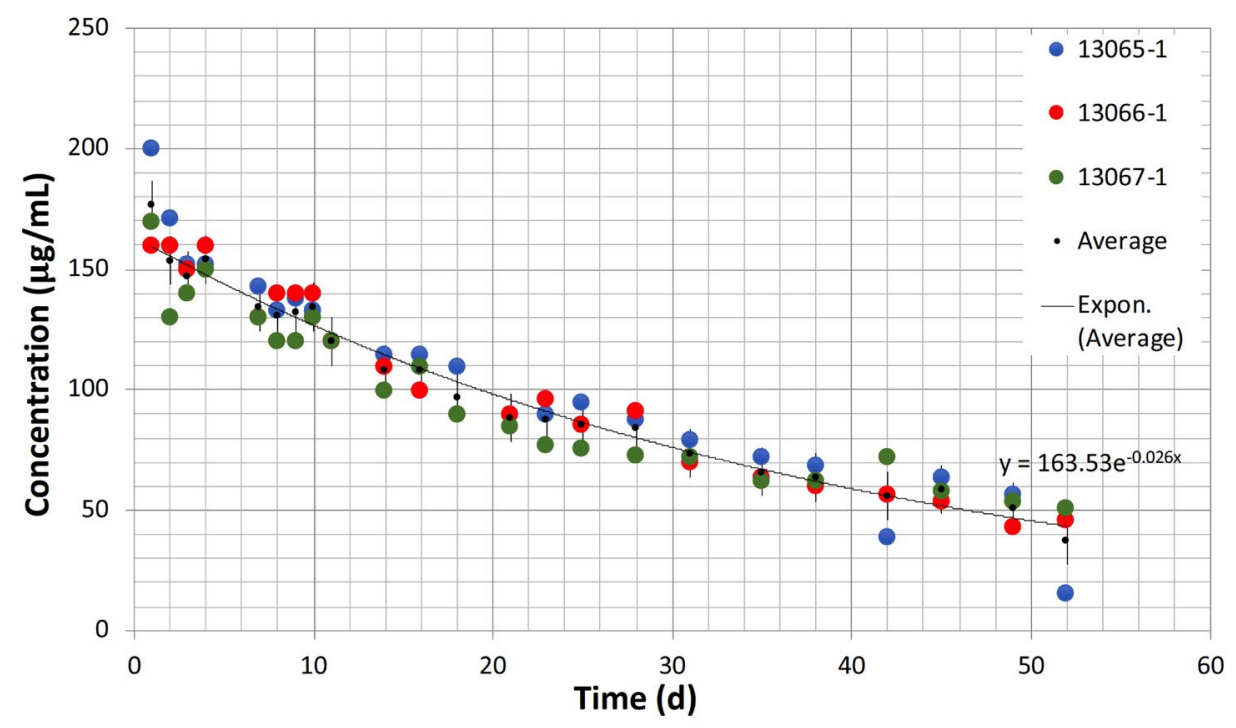

Fig. 3. Half-life of murine mAb $1 \mathrm{C11}$ in sheep. To determine basic pharmacokinetic parameters of candidate mouse $\mathrm{mAbs}$ in sheep, 3 candidate sheep were injected with murine 1C11 and the blood (serum) was collected for $52 \mathrm{~d}$ to measure the concentration of mouse IgG1. Fitting the averaged data to a single decay curve yielded an estimated circulating half-life of about $23.7 \mathrm{~d}$. 
clinically cured of S. aureus osteomyelitis. Fig. 5 shows the results of a post-hoc analysis that identified 12 patients whose immune proteome and clinical profile was consistent with a cured $S$. aureus osteomyelitis, in that they had $>20 \mu \mathrm{g} / \mathrm{mL}$ of anti-Gmd antibodies in their serum prior to treatment and displayed no clinical signs or symptoms of infection following treatment. Additionally, their circulating anti-Gmd antibody titers markedly decreased from baseline to 6-month time point. Thus, assuming insignificant endogenous anti-Gmd antibody synthesis following treatment, the mean half-life of anti-Gmd antibodies in this cohort was $120.4 \mathrm{~d}$, suggesting an approximately 3-month dosing regimen for passive-immunisation with a protective anti-Gmd $\mathrm{mAb}$ for this indication. Nonetheless, the primary intention of the anti-Gmd therapy is a one-time preventative treatment in patients lacking anti-Gmd antibodies that are about to undergo TKA/THA.

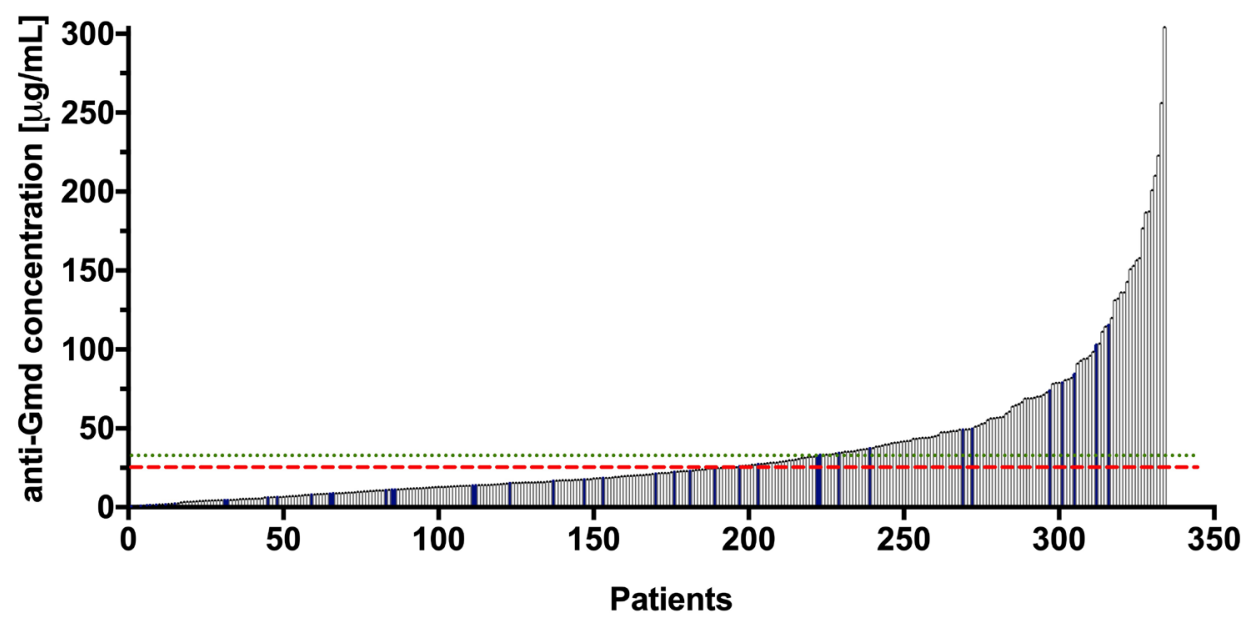

Fig. 4. Naturally occurring anti-Gmd antibody levels in serum from a large cohort of patients with $S$. aureus osteomyelitis. Serum was obtained from 297 patients with culture-confirmed S. aureus osteomyelitis (represented in black) and 40 healthy individuals (represented in blue) with no reported infections. The concentration of anti-Gmd antibodies in each sample was determined by Luminex assay as described in Fig. 2. The anti-Gmd concentrations $(\mu \mathrm{g} / \mathrm{mL})$ are presented in rank order from the lowest to the highest and ranged from undetectable $(<1 \mathrm{ng} / \mathrm{mL})$ to $304 \mu \mathrm{g} / \mathrm{mL}$. The concentration of anti-Gmd in the median patient was $21.7 \mu \mathrm{g} / \mathrm{mL}$. The red dashed line indicates the mean concentration of anti-Gmd $(25.6 \pm 28.6 \mu \mathrm{g} / \mathrm{mL}) \mathrm{in}$ sera of 40 uninfected healthy controls and the green dotted line is the $95 \% \mathrm{UCB}=33.2 \mu \mathrm{g} / \mathrm{mL}$.

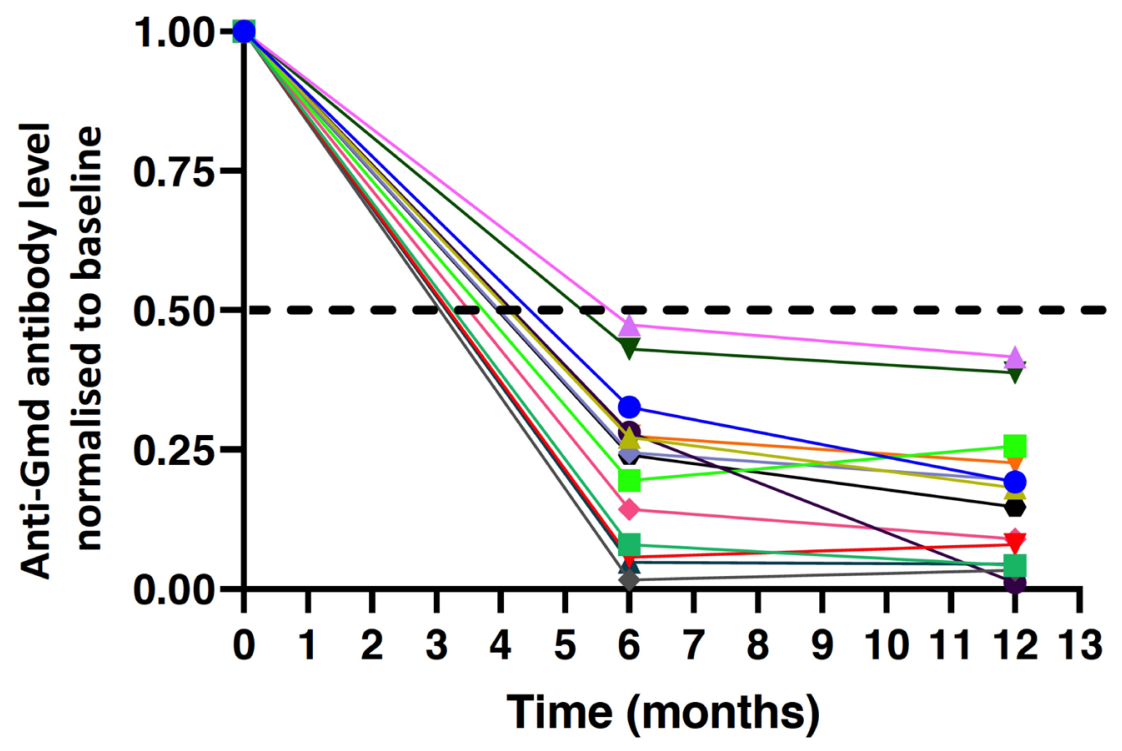

Fig. 5. Analysis of endogenous anti-Gmd antibody level decay in patients with cured S. aureus osteomyelitis. A post-hoc analysis was performed on the S. aureus-infected cohort to identify a cured subgroup that had $>20 \mu \mathrm{g} / \mathrm{mL}$ of anti-Gmd antibodies in their serum prior to treatment and who displayed no clinical signs or symptoms of infection following treatment. Anti-Gmd antibody levels in the sera of the 12 patients identified in the cured sub-group were determined by Luminex assay and normalised values based on each patient's anti-Gmd antibody level at 0 months (baseline) are presented. Assuming insignificant endogenous anti-Gmd antibody synthesis following treatment, the mean half-life of anti-Gmd antibodies in the cohort was $120.4 \mathrm{~d}$. 


\section{Discussion}

An effective immunotherapy against the primary pathogen responsible for most musculoskeletal infections would be transformative for orthopaedic surgery. Unfortunately, none exists and a major contributing factor to failures in $S$. aureus vaccine development has been the absence of an in vivo model with face and construct validity of surgical site infections (Reizner et al., 2014; Salgado-Pabon and Schlievert, 2014). Thus, the approach to develop a passive immunisation has focused on murine models with quantitative outcomes of in vivo planktonic growth, biofilm bacteria on the implants, SACs, invasion and colonisation of the osteocyticcanalicular network of cortical bone, osteolysis and implant osseointegration (de Mesy Bentley et al., 2017; Inzana et al., 2015; Li et al., 2008; Nishitani et al., 2015b; Varrone et al., 2014; Yokogawa et al., 2018). Also, a sheep model of a failed two-stage revision of intramedullary-nail-related infection by MRSA was developed (Moriarty et al., 2017), which is a suitable model for testing passive immunisation.

Concerning the vaccine's molecular mechanism of action, the study hypothesis was that an ideal passive immunotherapy would be an $\mathrm{mAb}$ with both direct antimicrobial effects through inhibition of a critical $S$. aureus target and immunomodulatory activity to enhance host response and bacterial clearance. From a non-biased antigen discovery, in vitro, animal model and clinical research point of view, Gmd was identified as a validated target for immunotherapy (Gedbjerg et al., 2013; Nishitani et al., 2015a; Oh et al., 2018; Varrone et al., 2014; Varrone et al., 2011b). Additionally, a lead anti-Gmd mAb (1C11) was developed over 36 candidates, based on its superior in vitro characteristics (Gedbjerg et al., 2013; Nishitani et al., 2015a; Oh et al., 2018; Varrone et al., 2014; Varrone et al., 2011b) and its safety and efficacy in prophylactic and therapeutic murine models of implant-associated MRSA osteomyelitis (Varrone et al., 2014; Yokogawa et al., 2018). Remarkably, the results show that $1 \mathrm{C} 11$ synergises with the standardof-care antibiotic therapy (vancomycin) in the 1-stage exchange model of MRSA through distinct mechanisms of actions, as vancomycin decreases the bacterial burden on the implant, but only anti-Gmd $\mathrm{mAb}$ inhibits SACs (Yokogawa et al., 2018). Thus, given its potential as an adjuvant therapy for PJI, the study aimed to further substantiate the feasibility of antiGmd $\mathrm{mAb}$ passive immunisation by: 1) demonstrating safety and favourable pharmacokinetics following a clinically relevant dose in sheep, 2) defining serum levels of anti-Gmd antibodies in patients with $S$. aureus osteomyelitis.

From a feasibility standpoint it is important to note that $\mathrm{mAb}$ therapies have been broadly adopted into virtually all areas of medicine and that maturity of this form of biological therapy has recently evolved to generic drugs, known as biosimilars (Ishii-Watabe and Kuwabara, 2019). While subcutaneous mAb therapies exist (Adalimumab, Denosumab, Secukinumab, etc.), most $\mathrm{mAb}$ drugs were initially approved as i.v. formulations, partly due to the higher fidelity of this form of dosing regimen for study in clinical trials. Moreover, the $1^{\text {st }}$ generation chimaeric $\mathrm{mAb}$ therapies (e.g. infliximab Remicade ${ }^{\circledR}$, trastuzumab Herceptin ${ }^{\circledR}$, rituximab Rituxan ${ }^{\circledR}$ ) are still administered to patients this way. Based on the well-established formulation of these mAbs, which broadly conform to an i.v. infusion of $~ 500 \mathrm{mg} / \mathrm{L}$ saline $(7 \mathrm{mg} / \mathrm{kg}$ for a $70 \mathrm{~kg}$ patient), this bolus dose was evaluated in sheep, whose mass is $~ 75 \%$ of that of a human. An important initial finding of this experiment was the ease of manufacturing $1 \mathrm{C} 11$ as a drug (Fig. 1) and its transport frozen from Rochester, New York, USA to Davos, Switzerland, without significant loss of material or potency (no significant mAb degradation or aggregation). While the absence of any adverse events during and $52 \mathrm{~d}$ following the i.v. infusion of $500 \mathrm{mg}$ of murine $1 \mathrm{C} 11 \mathrm{mAb}$ into the 3 sheep was not surprising, the $23.7 \mathrm{~d}$ circulating half-life of the $\mathrm{mAb}$ in this xenogeneic host (Fig. 3) was beyond expectations based on immunogenicity concerns. However, those findings in a very small sample size $(n=3)$ cannot be generalised and this simple proof-ofconcept study was not meant to circumvent the very rigorous preclinical safety and toxicology studies required to justify the use of an anti-Gmd $\mathrm{mAb}$ in human patients.

A major safety advantage of anti-Gmd mAb over biologics that target host factors (e.g. anti-cytokine $\mathrm{mAb}$ ) is that the $\mathrm{mAb}$ binds to a bacterial gene product that does not exist in humans. Thus, the potential off-target effects of this $\mathrm{mAb}$ are very limited and $\mathrm{Gmd}$ is expected to be highly immunogenic in people, as recombinant Gmd protein is highly immunogenic in experimental animals grown in germ-free environments (Brady et al., 2011; Varrone et al., 2011a). A major theoretical concern with anti-Gmd $\mathrm{mAb}$ passive immunisation was that it would be superfluous to the patient's endogenous antiGmd antibodies. Therefore, the remarkable finding that $65 \%$ of patients with active S. aureus osteomyelitis failed to generate circulating anti-Gmd IgG titers above that of healthy control sera (Fig. 4) and commercially available i.v. IgG (Rongsheng ${ }^{\circledR}$ Human Immunoglobulin, pH 4, i.v. injection, $50 \mathrm{~g} / \mathrm{L}$, Chengdu Rongsheng Pharmaceuticals Co., Ltd. Chengdu, Sichuan, China. Intravenous immunoglobulin contains $38.36 \mu \mathrm{g} / \mathrm{mL}$ of anti-Gmd antibody, data not shown) suggested that these patients cannot generate humoral immunity against this critical antigen on their own and that antiGmd passive immunisation was indicated for them. While this conclusion was based on the calculations of endogenous anti-Gmd levels in human sera that were validated by Luminex assay, it should be noted that a limitation of the approach was the use of a single purified $\mathrm{mAb}(1 \mathrm{C} 11)$ to quantify polyclonal anti-Gmd antibodies in human sera.

To better understand anti-Gmd immunity, as a future direction, the functionality of the anti-Gmd antibodies from the patients with very high titers $(>100 \mu \mathrm{g} / \mathrm{mL}$, 
$n=23$, Fig. 4) has to be assessed, as the non-protective effect of these anti-Gmd antibodies could be due to their inability to neutralise Gmd enzymatic activity or to contain an inappropriate Fc (i.e. IgG4) that is incapable of fixing complement and/or mediating opsonophagocytosis by activated leukocytes. Lastly, as the standard-of-care antibiotic therapy for chronic S. aureus osteomyelitis is given over long periods (months) and definitive cure cannot be established with less than 6-weeks of treatment, the study aimed to gain insight on the number of anti-Gmd mAb doses needed during the 1-year treatment period following confirmed $S$. aureus osteomyelitis by determining the decay of endogenous anti-Gmd antibodies in patients with a cured phenotype (Fig. 5). Although the calculated half-life of $120.4 \mathrm{~d}$ was an overestimate, as it unreasonably assumed no de novo anti-Gmd antibody production following the baseline blood draw and autogenous antibodies have higher stability than biologics, the 3 to 4 infusions per year that this predicts is consistent with cancer immunotherapies (ipilimumab Yervoy ${ }^{\circledR}$, pembrolizumab Keytruda ${ }^{\circledR}$, nivolumab Opdivo ${ }^{\circledR}$ ) (Schwarz et al., 2019). Although more stringent experiments could be performed, formal assessments of biodistribution and circulating anti-Gmd mAb half-life are not warranted until a drug for clinical trials is available.

\section{Conclusions}

Based on its dual mechanisms of action that includes direct antimicrobial effects and immunomodulation, anti-Gmd $\mathrm{mAb}$ passive immunisation has emerged as a potential prophylaxis for patients at high-risk of surgical-site infections and as an adjuvant to antibiotic therapy for $S$. aureus osteomyelitis. Towards clinical trials, the present study established that an anti-Gmd $\mathrm{mAb}$ had favourable drug manufacturing and storage characteristics and that a clinically relevant dose $(8.9 \mathrm{mg} / \mathrm{kg} / \mathrm{i} . \mathrm{v}$.) was safe in sheep. AntiGmd mAb therapy was warranted for the majority of patients with active $S$. aureus osteomyelitis who failed to develop humoral immunity against Gmd.

\section{Acknowledgements}

This work was supported by research grants from the National Institutes of Health (P30 AR069655 and P50 AR72000) and AOTrauma Clinical Priority Program.

\section{References}

Azzam K, McHale K, Austin M, Purtill JJ, Parvizi J (2009) Outcome of a second two-stage reimplantation for periprosthetic knee infection. Clin Orthop Relat Res 467: 1706-1714.

Bagnoli F, Bertholet S, Grandi G (2012) Inferring reasons for the failure of Staphylococcus aureus vaccines in clinical trials. Front Cell Infect Microbiol 2: 16. DOI: 10.3389/fcimb.2012.00016.

Binsker U, Palankar R, Wesche J, Kohler TP, Prucha J, Burchhardt G, Rohde M, Schmidt F, Broker BM, Mamat U, Pane-Farre J, Graf A, Ebner P, Greinacher A, Hammerschmidt S (2018) Secreted immunomodulatory proteins of Staphylococcus aureus activate platelets and induce platelet aggregation. Thromb Haemost 118: 745-757.

Birt MC, Anderson DW, Bruce Toby E, Wang J (2017) Osteomyelitis: recent advances in pathophysiology and therapeutic strategies. J Orthop 14: 45-52.

Brady RA, Leid JG, Camper AK, Costerton JW, Shirtliff ME (2006) Identification of Staphylococcus aureus proteins recognized by the antibody-mediated immune response to a biofilm infection. Infect Immun 74: 3415-3426.

Brady RA, O’May GA, Leid JG, Prior ML, Costerton JW, Shirtliff ME (2011) Resolution of Staphylococcus aureus biofilm infection using vaccination and antibiotic treatment. Infect Immun 79: 1797-1803.

Cheng AG, Kim HK, Burts ML, Krausz T, Schneewind O, Missiakas DM (2009) Genetic requirements for Staphylococcus aureus abscess formation and persistence in host tissues. FASEB J 23: 3393-3404.

Cram P, Lu X, Kates SL, Singh JA, Li Y, Wolf BR (2012) Total knee arthroplasty volume, utilization, and outcomes among Medicare beneficiaries, 19912010. JAMA 308: 1227-1236.

Darouiche RO (2004) Treatment of infections associated with surgical implants. N Engl J Med 350: 1422-1429.

de Mesy Bentley KL, MacDonald A, Schwarz EM, Oh I (2018) Chronic osteomyelitis with Staphylococcus aureus deformation in submicron canaliculi of osteocytes: a case report. JBJS Case Connect 8: e8. DOI: 10.2106/JBJS.CC.17.00154.

de Mesy Bentley KL, Trombetta R, Nishitani K, Bello-Irizarry SN, Ninomiya M, Zhang L, Chung HL, McGrath JL, Daiss JL, Awad HA, Kates SL, Schwarz EM (2017) Evidence of Staphylococcus aureus deformation, proliferation, and migration in canaliculi of live cortical bone in murine models of osteomyelitis. J Bone Miner Res 32: 985-990.

Eirich J, Orth R, Sieber SA (2011) Unraveling the protein targets of vancomycin in living $S$. aureus and E. faecalis cells. J Am Chem Soc 133: 12144-12153.

Ferry T, Uckay I, Vaudaux P, Francois P, Schrenzel J, Harbarth S, Laurent F, Bernard L, Vandenesch F, Etienne J, Hoffmeyer P, Lew D (2009) Risk factors for treatment failure in orthopedic device-related methicillin-resistant Staphylococcus aureus infection. Eur J Clin Microbiol Infect Dis 29: 171-180.

Fowler VG, Allen KB, Moreira ED, Moustafa M, Isgro F, Boucher HW, Corey GR, Carmeli Y, Betts R, Hartzel JS, Chan IS, McNeely TB, Kartsonis NA, Guris D, Onorato MT, Smugar SS, DiNubile MJ, Sobanjo-ter Meulen A (2013) Effect of an investigational vaccine for preventing Staphylococcus aureus infections after 
cardiothoracic surgery: a randomized trial. JAMA 309: 1368-1378.

Fowler VG Jr, Proctor RA (2014) Where does a Staphylococcus aureus vaccine stand? Clin Microbiol Infect 20 Suppl 5: 66-75.

Gedbjerg N, Larosa R, Hunter JG, Varrone JJ, Kates SL, Schwarz EM, Daiss JL (2013) Anti-glucosaminidase IgG in sera as a biomarker of host immunity against Staphylococcus aureus in orthopaedic surgery patients. J Bone Joint Surg Am 95: e1711-1719.

Ghanem E, Azzam K, Seeley M, Joshi A, Parvizi J (2009) Staged revision for knee arthroplasty infection: what is the role of serologic tests before reimplantation? Clin Orthop Relat Res 467: 1699-1705.

Gotz F, Heilmann C, Stehle T (2014) Functional and structural analysis of the major amidase (Atl) in Staphylococcus. Int J Med Microbiol 304: 156-163.

Harro CD, Betts RF, Hartzel JS, Onorato MT, Lipka J, Smugar SS, Kartsonis NA (2012) The immunogenicity and safety of different formulations of a novel Staphylococcus aureus vaccine (V710): results of two phase I studies. Vaccine 30: 1729-1736.

Heilmann C, Hartleib J, Hussain MS, Peters G (2005) The multifunctional Staphylococcus aureus autolysin aaa mediates adherence to immobilized fibrinogen and fibronectin. Infect Immun 73: 47934802.

Hirschhausen N, Schlesier T, Schmidt MA, Gotz F, Peters G, Heilmann C (2010) A novel staphylococcal internalization mechanism involves the major autolysin Atl and heat shock cognate protein Hsc70 as host cell receptor. Cell Microbiol 12: 1746-1764.

Holtfreter S, Kolata J, Broker BM (2010) Towards the immune proteome of Staphylococcus aureus - the anti-S. aureus antibody response. Int J Med Microbiol 300: 176-192.

Inzana JA, Schwarz EM, Kates SL, Awad HA (2015) A novel murine model of established staphylococcal bone infection in the presence of a fracture fixation plate to study therapies utilizing antibiotic-laden spacers after revision surgery. Bone 72: 128-136.

Ishii-Watabe A, Kuwabara T (2019) Biosimilarity assessment of biosimilar therapeutic monoclonal antibodies. Drug Metab Pharmacokinet 34: 64-70.

Jansen KU, Girgenti DQ, Scully IL, Anderson AS (2013) Vaccine review: "Staphyloccocus aureus vaccines: problems and prospects". Vaccine 31: 27232730.

Kalali Y, Haghighat S, Mahdavi M (2019) Passive immunotherapy with specific IgG fraction against autolysin: analogous protectivity in the MRSA infection with antibiotic therapy. Immunol Lett 212: 125-131.

Kates SL, Hurni S, Chen MS (2019) Development and challenges in setting up an international bone infection registry. Arch Orthop Trauma Surg: 1-9. DOI: 10.1007/s00402-019-03303-7.

Kim HK, DeDent A, Cheng AG, McAdow M, Bagnoli F, Missiakas DM, Schneewind O (2010) Isd A and IsdB antibodies protect mice against
Staphylococcus aureus abscess formation and lethal challenge. Vaccine 28: 6382-6392.

Kurtz SM, Lau E, Watson H, Schmier JK, Parvizi J (2012) Economic burden of periprosthetic joint infection in the United States. J Arthroplasty 27: 61-65.

Lew DP, Waldvogel FA (2004) Osteomyelitis. Lancet 364: 369-379.

Li D, Gromov K, Soballe K, Puzas JE, O'Keefe RJ, Awad H, Drissi H, Schwarz EM (2008) Quantitative mouse model of implant-associated osteomyelitis and the kinetics of microbial growth, osteolysis, and humoral immunity. J Orthop Res 26: 96-105.

Masters E, Trombetta RP, de Mesy Bentley KL, Boyce BF, Gill A, Gill SR, Nishitani K, Ishikawa M, Morita Y, Bello-Irizarry SN, Ninomiya M, Brodell JD, Lee CC, Hao SP, Oh I, Xie C, Awad HA, Daiss JL, Owen JR, Kates SL, Schwarz EM, Muthukrishnan G (2019) Evolving concepts in bone infection: redefining "biofilm", "acute vs. chronic osteomyelitis", "the immune proteome" and "local antibiotic therapy". Bone Res 7: 20. doi: 10.1038/s41413-019-0061-z.

McNeely TB, Shah NA, Fridman A, Joshi A, Hartzel JS, Keshari RS, Lupu F, DiNubile MJ (2014) Mortality among recipients of the Merck V710 Staphylococcus aureus vaccine after postoperative $S$. aureus infections: an analysis of possible contributing host factors. Hum Vaccin Immunother 10: 3513-3516.

Moriarty TF, Schmid T, Post V, Samara E, Kates S, Schwarz EM, Zeiter S, Richards RG (2017) A large animal model for a failed two-stage revision of intramedullary nail-related infection by methicillinresistant Staphylococcus aureus. Eur Cell Mater 34: 83-98.

Nishitani K, Beck CA, Rosenberg AF, Kates SL, Schwarz EM, Daiss JL (2015a) A diagnostic serum antibody test for patients with Staphylococcus aureus osteomyelitis. Clin Orthop Relat Res 473: 2735-2749.

Nishitani K, Sutipornpalangkul W, de Mesy Bentley KL, Varrone JJ, Bello-Irizarry SN, Ito H, Matsuda S, Kates SL, Daiss JL, Schwarz EM (2015b) Quantifying the natural history of biofilm formation in vivo during the establishment of chronic implantassociated Staphylococcus aureus osteomyelitis in mice to identify critical pathogen and host factors. J Orthop Res 33: 1311-1319.

Oh I, Muthukrishnan G, Ninomiya MJ, Brodell JD, Jr., Smith BL, Lee CC, Gill SR, Beck CA, Schwarz EM, Daiss JL (2018) Tracking anti-Staphylococcus aureus antibodies produced in vivo and ex vivo during foot salvage therapy for diabetic foot infections reveals prognostic insights and evidence of diversified humoral immunity. Infect Immun 86. pii: e00629-18. DOI: 10.1128/IAI.00629-18.

Oshida T, Sugai M, Komatsuzawa H, Hong YM, Suginaka H, Tomasz A (1995) A Staphylococcus aureus autolysin that has an $\mathrm{N}$-acetylmuramoyl$\mathrm{L}$-alanine amidase domain and an endo-beta-Nacetylglucosaminidase domain: cloning, sequence analysis, and characterization. Proc Natl Acad Sci U S A 92: 285-289. 
Parvizi J, Azzam K, Ghanem E, Austin MS, Rothman RH (2009) Periprosthetic infection due to resistant staphylococci: serious problems on the horizon. Clin Orthop Relat Res 467: 1732-1739.

Pier GB (2013) Will there ever be a universal Staphylococcus aureus vaccine? Hum Vaccin Immunother 9: 1865-1876.

Proctor RA (2012) Is there a future for a Staphylococcus aureus vaccine? Vaccine 30: 2921-2927.

Proctor RA (2015) Recent developments for Staphylococcus aureus vaccines: clinical and basic science challenges. Eur Cell Mater 30: 315-326.

Projan SJ, Nesin M, Dunman PM (2006) Staphylococcal vaccines and immunotherapy: to dream the impossible dream? Curr Opin Pharmacol 6: 473-479.

Reizner W, Hunter JG, O'Malley NT, Southgate RD, Schwarz EM, Kates SL (2014) A systematic review of animal models for Staphylococcus aureus osteomyelitis. Eur Cell Mater 27: 196-212.

Saeed K, McLaren AC, Schwarz EM, Antoci V, Arnold WV, Chen AF, Clauss M, Esteban J, Gant V, Hendershot E, Hickok N, Higuera CA, Coraca-Huber DC, Choe H, Jennings JA, Joshi M, Li WT, Noble PC, Phillips KS, Pottinger PS, Restrepo C, Rohde H, Schaer TP, Shen H, Smeltzer M, Stoodley P, Webb JCJ, Witso E (2019) 2018 international consensus meeting on musculoskeletal infection: summary from the biofilm workgroup and consensus on biofilm related musculoskeletal infections. J Orthop Res 37: 10071017.

Salgado CD, Dash S, Cantey JR, Marculescu CE (2007) Higher risk of failure of methicillin-resistant Staphylococcus aureus prosthetic joint infections. Clin Orthop Relat Res 461: 48-53.

Salgado-Pabon W, Schlievert PM (2014) Models matter: the search for an effective Staphylococcus aureus vaccine. Nat Rev Microbiol 12: 585-591.

Schwarz EM, Parvizi J, Gehrke T, Aiyer A, Battenberg A, Brown SA, Callaghan JJ, Citak M, Egol K, Garrigues GE, Ghert M, Goswami K, Green A, Hammound S, Kates SL, McLaren AC, Mont MA, Namdari S, Obremskey WT, O'Toole R, Raikin S, Restrepo C, Ricciardi B, Saeed K, Sanchez-Sotelo J, Shohat N, Tan T, Thirukumaran CP, Winters B (2019) 2018 International consensus meeting on musculoskeletal infection: research priorities from the general assembly questions. J Orthop Res 37: 997-1006.

Smyth MJ, Teng MW (2018) 2018 Nobel Prize in physiology or medicine. Clin Transl Immunology 7: e1041.

Stulberg JJ, Delaney CP, Neuhauser DV, Aron DC, Fu P, Koroukian SM (2010) Adherence to surgical care improvement project measures and the association with postoperative infections. JAMA 303: 2479-2485.

Sugai M, Komatsuzawa H, Akiyama T, Hong YM, Oshida T, Miyake Y, Yamaguchi T, Suginaka H (1995) Identification of endo-beta-N-acetylglucosaminidase and N-acetylmuramyl-L-alanine amidase as cluster- dispersing enzymes in Staphylococcus aureus. J Bacteriol 177: 1491-1496.

Varrone JJ, de Mesy Bentley KL, Bello-Irizarry SN, Nishitani K, Mack S, Hunter JG, Kates SL, Daiss JL, Schwarz EM (2014) Passive immunization with anti-glucosaminidase monoclonal antibodies protects mice from implant-associated osteomyelitis by mediating opsonophagocytosis of Staphylococcus aureus megaclusters. J Orthop Res 32: 1389-1396.

Varrone JJ, Li D, Daiss JL, Schwarz EM (2011a) Anti-glucosaminidase monoclonal antibodies as a passive immunization for methicillin-resistant Staphylococcus aureus (MRSA) orthopaedic infections. Bonekey Osteovision 8: 187-194.

Varrone JJ, Li D, Daiss JL, Schwarz EM (2011b) Anti-glucosaminidase monoclonal antibodies as a passive immunization for methicillin-resistant Staphylococcus aureus (MRSA) orthopedic infections. IBMS Bonekey 8: 187-194.

Yamada S, Sugai M, Komatsuzawa H, Nakashima S, Oshida T, Matsumoto A, Suginaka H (1996) An autolysin ring associated with cell separation of Staphylococcus aureus. Journal of Bacteriology 178: 1565-1571.

Yokogawa N, Ishikawa M, Nishitani K, Beck CA, Tsuchiya H, Mesfin A, Kates SL, Daiss JL, Xie C, Schwarz EM (2018) Immunotherapy synergizes with debridement and antibiotic therapy in a murine 1-stage exchange model of MRSA implant-associated osteomyelitis. J Orthop Res 36: 1590-1598.

\section{Discussion with Reviewer}

Kunt Ohlsen: Why have you selected sheep for the pharmacokinetics study?

Authors: The researchers of the AO Research Institute are experts in sheep models, particularly for orthopaedic implants. With that in mind, we felt that sheep would be a reasonable model for antibody prophylaxis of implant-associated infections. Also, sheep are similar to humans in weight.

Kunt Ohlsen: How relevant are sheep as compared to other animal models?

Authors: Sheep and goats are now considered to be the primary large animal models for orthopaedic trauma studies based on ethical concerns in using canine and non-human primates, their similar mass to humans and cost-effectiveness.

Kunt Ohlsen: What is known on the anti-Gmd antibodies found in patients surviving osteomyelitis? Authors: We are currently characterising the antiGmd antibodies in these patients and intend to publish the physical bind properties and Gmd inhibition data in a subsequent publication, together with IgG4 anti-Gmd antibody titers. We are also preparing a publication focused on correlating the serology with clinical outcomes of the entire cohort. 
Kunt Ohlsen: Why do the authors think that a humanisation is not necessary since osteomyelitis treatment is longer than any other type of infection? Authors: While we agree that a fully human antiGmd $\mathrm{mAb}$ would be better, there are FDA-approved chimaeric antibodies that are used to treat life-long diseases (e.g. infliximab for Crohn's disease and rheumatoid arthritis). Thus, it is established that humanisation of chimaeric $\mathrm{mAb}$ is not necessary for long-term treatments.

Editor's note: The Scientific Editor responsible for this paper was Mauro Alini. 